\title{
Diseño de la ruta turística cultural "Laberinto de leyendas y tradiciones"
}

\section{Title: Design of the cultural route "Maze of legends and traditions."}

Arlette Arceo Martínez. ${ }^{1}$ \& Adriel Malvarez Cuello. ${ }^{2}$

\begin{abstract}
.
Camagüey city have a great cultural tradition,that allows to take advantage for tourism developh, in the city tourism modality, like a part of cultural tourism. However, they have not been possible to conceptualize the historical-cultural values of the same one in an offer capable of potentialize their attractiveness and tourist products. This project proposes the cultural route "Maze of legends and traditions", based in first place in the smart use of the attractiveness from the city and it looking for satisfy the necessities of the segment of the demand objective. Using a Marketing point of view, the tourist route is designed, after analyze all of the marketing-mix variables (Product, Price, Promotion and Place).Also, this study contains and economic and environmental factibility analysis, and a proposal of strategical actions to do when the product will be launch to the market, in his first fase of life.
\end{abstract}

Keywords: tourist route, cultural tourism, Camagüey, design, marketing.

\section{Resumen.}

La ciudad de Camagüey posee una gran tradición cultural, que permite sacar provecho de la misma para el desarrollo de la actividad turística en la modalidad de turismo de ciudad como parte del turismo cultural. Sin embargo, todavía no se han logrado conceptualizar los valores histórico-culturales de la misma en una oferta capaz de potencializar sus atractivos y productos turísticos. El presente proyecto es una propuesta de ruta turística cultural «Laberinto de leyendas y tradiciones» que se basa fundamentalmente en el aprovechamiento de los atractivos de esta ciudad y que busca satisfacer las necesidades

\footnotetext{
${ }^{1}$ Facultad de Turismo-Universidad de La Habana, Cuba arceomartinezarlette@gmail.com

${ }^{2}$ Facultad de Turismo-Universidad de La Habana, Cuba. adrielmalva2017@gmail.com
} 
del segmento de la demanda objetivo. Basados en un enfoque de Marketing, se diseña la ruta turística ya mencionada analizando cada una de las variables que componen la mezcla de mercadotecnia (Producto, Precio, Promoción, Distribución). Además se hace una análisis de la factibilidad económica y medioambiental de la misma, así como una propuesta de acciones estratégicas a implementar para el lanzamiento del producto al mercado en su primera fase de vida.

Palabras clave: Ruta turística, turismo cultural, Camagüey, diseño, marketing.

\section{Introducción}

Cuba se ha convertido, en los últimos años, en un destino turístico muy popular, por lo que las principales políticas están enfocadas en aumentar la competitividad del país en el mercado turístico mundial a partir de la diversificación de la oferta turística de manera general, con la creación de nuevos productos y el logro de una adecuada coherencia en la relación calidad-precio; tal como se expresa en el Lineamiento No. 257, aprobado en el VI Congreso del Partido Comunista de Cuba (PCC).

El turismo de Sol y Playa es la modalidad que prevalece en el país debido a los atractivos y recursos que posee para el desarrollo de la misma. No obstante, en los últimos años han cobrado auge otras modalidades tales como: el turismo de naturaleza, el turismo de cruceros, el turismo de eventos e incentivos y el turismo cultural. Este último es desarrollado fundamentalmente en las principales ciudades del país y sus centros históricos, puesto que Cuba cuenta con una riqueza patrimonial que atesora siglos de historia y su legado ha traspasado los límites nacionales para alcanzar renombre internacional. ( Colectivo de autores, 2009)El país tiene el privilegio de contar con varios sitios inscritos en la lista del Patrimonio de la Humanidad entre ellos: el Centro Histórico de La Habana y su sistema de fortificaciones coloniales, el Centro Histórico Urbano de Trinidad y el Valle de los Ingenios en Sancti Spíritus, el Castillo del Morro de San Pedro de la Roca en Santiago de Cuba, el Centro Histórico Urbano de la ciudad Cienfuegos y el Centro Histórico de la ciudad Camagüey, entre otros.

La ciudad Camagüey posee una tradición cultural amplísima, lo que hace de la misma un espacio idóneo para sacar amplios provechos de la actividad turística en su modalidad citadina. El Centro Histórico de Camagüey, catalogado entre los más extensos y antiguos del país, concentra importantes valores socioculturales y patrimoniales que lo convierten en un sitio perfecto para el desarrollo de la actividad turística. La trama urbana del centro histórico se distingue y singulariza no sólo de otros centros históricos de la nación, sino del resto de las áreas urbanizadas de la ciudad. Su trazado irregular, es un ejemplo único en el país, calles estrechas y callejones se dilatan para formar un interesante conjunto de plazuelas y plazas a las que se vincula una rica tradición histórica y cultural. (Fernández, s.f.) 
Indudablemente, la ciudad es poseedora del patrimonio, la cultura y la historia, pero debe hacerse aún más atractivo el destino mediante la creación de rutas y excursiones únicas que superen las expectativas de los visitantes y hagan de la ciudad camagüeyana un lugar de necesaria visita.

Al realizar un análisis de la situación en la ciudad Camagüey se encontró que resulta insuficiente la gestión de Marketing realizada en el territorio en cuanto a los atractivos y productos turísticos que posee, lo que se observa en el indicador Estancia Promedio Total reportado en la Oficina Nacional de Estadísticas e Información. Lo que reafirma que la ciudad se utiliza como un lugar de tránsito y no como un destino turístico. Este aspecto, atenta contra el éxito del Lineamiento No. 261, aprobado en el VI Congreso del PCC, referido a: «Perfeccionar la comunicación promocional a nivel institucional y empresarial, precisando la administración de los recursos y su asignación por mercados y técnicas, con la utilización de tecnología de avanzada».

En correspondencia con lo anterior, se encuentra que a pesar de que en los últimos años se ha estado realizando un rescate del patrimonio cultural de la ciudad, aún no se han logrado potencializar los atractivos turísticos culturales de la misma.

Esto, atenta contra el éxito de los Lineamientos siguientes:

No. 264. «Diseñar y desarrollar como parte de la iniciativa municipal por los territorios, ofertas turísticas atractivas como fuente de ingreso en divisas (alojamiento, servicios gastronómicos, actividades socioculturales e históricas, ecuestres, de campiñas, turismo rural, observación de la flora y la fauna, entre otras)».

No. 260. «Crear, diversificar y consolidar de forma acelerada servicios y ofertas complementarias al alojamiento que distingan al país, priorizando el desarrollo de las modalidades: turismo de salud, marinas y náutica, golf e inmobiliaria, turismo de aventura y naturaleza, parques temáticos, crucerismo, historia, cultura y patrimonio, convenciones, congresos y ferias, entre otras, incluyendo el estudio de las potencialidades en la costa sur».

Teniendo en cuenta lo expuesto anteriormente, los autores plantean el siguiente Problema Científico: ¿Cómo contribuir a la potencialización de los atractivos y productos turísticos culturales de la ciudad Camagüey?

A partir del problema científico enunciado, se formuló la hipótesis siguiente:

El diseño de una ruta turística cultural, contribuirá a potencializar los atractivos y productos turísticos culturales de la ciudad Camagüey. En aras de cumplimentarla se trazó como objetivo general: Diseñar una ruta turística cultural que potencie los atractivos y productos turísticos culturales de la ciudad Camagüey. 


\section{Objetivos específicos:}

- Analizar el macro y microentorno en el que se inserta la propuesta de ruta turística cultural que potencializarán los atractivos y productos turísticos culturales de la ciudad Camagüey.

- Caracterizar el segmento de demanda objetivo que justifica la propuesta de ruta turística cultural que potencializarán los atractivos y productos turísticos culturales de la ciudad Camagüey.

- Definir los valores culturales de la propuesta de ruta turística cultural que potencializarán los atractivos y productos turísticos culturales de la ciudad Camagüey.

- Determinar el Marketing Mix de la propuesta de ruta turística cultural que potencializarán los atractivos y productos turísticos culturales de la ciudad Camagüey.

- Analizar la factibilidad económica y medioambiental de la propuesta de ruta turística cultural que potencializarán los atractivos y productos turísticos culturales de la ciudad Camagüey.

\section{Metodología.}

Los objetivos propuestos se cumplimentaron a partir de la aplicación de métodos teóricos, empíricos, matemáticos y estadísticos siguientes:

\section{Métodos teóricos}

- Análisis bibliográfico: Se emplea para determinar los referentes bibliográficos que se corresponden con la propuesta de investigación, desde los puntos de vista de actualidad y contenido.

- Análisis-Síntesis: Se emplea para analizar y sintetizar los referentes teóricos y metodológicos a considerar durante el diseño de propuesta de ruta turística cultural «Laberinto de leyendas y tradiciones», así como la información obtenida en los restantes métodos, especialmente los resultados de las técnicas empleadas.

- Inductivo-Deductivo: Para identificar los elementos que caracterizan las situaciones problemáticas detectadas y deducir una solución práctica desde la ciencia, estableciendo vínculos entre los referentes teórico-metodológicos y datos recopilados a través de la búsqueda bibliográfica y el empleo de las técnicas previstas, partiendo siempre de lo general a lo específico de cada aspecto.

\section{Métodos empíricos}

- $\quad$ Encuesta: Para realizar la segmentación de la demanda.

- Entrevista: Para obtener la información necesaria de personal especializado perteneciente a TRANSTUR y la Agencia de Viajes Paradiso.

- Matriz DAFO: Para analizar las debilidades, amenazas, fortalezas y oportunidades del producto y tomar estrategias a seguir en consecuencia. 


\section{Métodos matemáticos}

- $\quad$ Análisis porcentual: Para el análisis de los resultados de la encuesta aplicada y de la información estadística obtenida.

\section{Métodos estadísticos}

Se utilizaron para el análisis de los resultados de la encuesta, mediante Microsoft Excel y Statistica 8.0; este último utilizando la técnica de análisis de clúster, para la segmentación de la demanda.

\section{Resultados.}

\section{Determinación de la muestra}

La aplicabilidad de los métodos se realizará a partir de la muestra seleccionada, para la que se tuvo en cuenta un muestreo no probabilístico intencional puro, para el que se seleccionaron personas posibles a clasificar en los segmentos trazados en la propuesta de ruta turística cultural. Teniendo en cuenta, el tiempo disponible para la investigación, los autores seleccionaron de la población de turistas hospedados en el Gran Hotel de la ciudad Camagüey, una muestra de 75 personas, utilizando para ello los criterios de selección siguientes: que fuesen turistas provenientes de Canadá, Alemania e Italia; que tengan una estancia media de dos o más días y mayores de 30 años de edad. A las personas que resultaron seleccionadas se les aplicó una encuesta.

\section{Análisis del entorno}

\section{Macroentorno según (Serra, 2003):}

\section{Entorno demográfico:}

La demografía del mercado proveniente principalmente de Canadá, Alemania e Italia que arriba al Centro Histórico de Camagüey se ha mantenido constante en los últimos cinco años. La estructura sociodemográfica de la demanda tiende a estar integrada por un público joven-adulto, activo, abarcando la mayor capa de la población teniendo como principales motivos de viaje ocio y recreación y el turismo cultural. Esta tendencia de consumo de este tipo de turismo constituye una oportunidad para el desarrollo del producto que se pretende implementar en este trabajo, ya que el mismo se encuentra dirigido a personas de todas las edades siempre y cuando se encuentren motivadas por el disfrute de productos culturales asociados al conocimiento y el aprendizaje; sin embargo, la mayoría de los jóvenes prefieren más los productos que incluyan diversión.

\section{Entorno político:}

Cuba goza de una gran estabilidad política, lo que ofrece seguridad a sus visitantes, atributo muy valorado por estos. Ello constituye una fortaleza para el desarrollo turístico del país, en el que intervienen entidades estatales como: migración, aduana general y autoridades sanitarias. 
Por otra parte, se han trazado políticas y legislaciones a nivel de país que contribuyen a impulsar dicho sector, lo que se evidencia a través de la actualización y conceptualización del Modelo Económico Cubano, en el que se reconoce la apertura de un nuevo sector encabezado por trabajadores por cuenta propia que se insertan también a esta actividad.

\section{Entorno económico:}

El entorno económico se está modificando a tono con el político. En este continúan existiendo problemas con respecto a la dualidad monetaria, las tasas de cambio, entre otros que pudieran resultar un inconveniente para algunos visitantes y, por lo tanto, afectaría a los turistas que consuman la oferta cultural propuesta. El éxito de esta propuesta generaría ingresos para el territorio, contribuiría a su desarrollo local y generaría empleos.

\section{Entorno ambiental:}

En Cuba se aboga por el desarrollo de un turismo sostenible en aras de conciliar los intereses de crecimiento económico con mejores condiciones de vida. Es una isla con un clima caluroso favorable; aunque es válido destacar que en el periodo de junio a noviembre transita por la temporada ciclónica, lo que constituye una amenaza para la oferta turística.

Atendiendo a lo planteado en la Ley de Medio Ambiente vigente, referida a la incorporación de la variable ambiental en las políticas, planes, proyectos, programas y demás acciones que realice en el sistema del turismo, los autores aseveran que la propuesta de ruta turística cultural «Laberinto de leyendas y tradiciones», cumple con la legislación vigente en materia medio ambiental; tal es así que, en la mayor parte del tiempo de esta, los turistas se transportan en bici-taxis.

\section{Entorno tecnológico:}

Teniendo en cuenta, que la propuesta de ruta turística cultural no requiere de infraestructura tecnológica para el desarrollo de la misma, los autores consideran favorable dicho aspecto. No obstante, ello no niega la utilidad de la Internet como canal para promover esta oferta.

\section{Entorno sociocultural:}

Cuba se ve beneficiada por la enorme riqueza que presenta su patrimonio cultural, por ello es reconocida internacionalmente. En el caso de Camagüey, es conocida como una de las ciudades más importantes del país, luego de La Habana y Santiago de Cuba, pues atesora el mayor centro histórico de Cuba, considerado entre los mejores conservados, y además ha sido declarado por la UNESCO como Patrimonio de la Humanidad; lo que beneficia el desarrollo de esta propuesta de ruta turística cultural. Por otra parte, se suma, el auge que ha cobrado la modalidad de Turismo Cultural, lo que constituye otro elemento beneficioso. Unido a esto, la población influye de una manera muy positiva para la realización de ofertas culturales, toda vez que el cubano siempre se ha caracterizado por 
su amabilidad y hospitalidad con los visitantes, además por su gran vinculación con los proyectos culturales.

\section{Microentorno:}

Tomando en cuenta las 5 fuerzas de Porter (1998), para la determinación de la rentabilidad a largo plazo de un segmento de la demanda, los autores aseveran lo siguiente:

\section{Entrada de competidores potenciales:}

Se ha observado un aumento notable del número de productos culturales en todo el país, debido al impulso que ha obtenido la modalidad de Turismo Cultural; lo que incentivó a los autores, diseñar la propuesta de ruta turística. Sin embargo, cada año salen al mercado ofertas novedosas que pudieran atentar contra el desarrollo exitoso de la misma. No obstante, actualmente no se observa la amenaza de nuevos competidores puesto que no se tiene conocimiento de que alguna empresa o AA. VV tenga previsto realizar un producto similar, que brinde el mismo beneficio para los clientes.

\section{Poder negociador de los proveedores:}

Para la implementación de este producto turístico se hace imprescindible la participación del proyecto artístico Andariego que brindan bici-taxis de la Empresa de Servicios Santa María, de la Oficina del Historiador de la Ciudad de Camagüey como medio de transporte, necesario para el recorrido por las estrechas calles de Camagüey. Por otra parte, contará con la Empresa TRANSTUR S.A, para el traslado de los clientes durante 5 horas en la tarde y en la noche. En este caso el poder de negociación que se establece con dicha empresa puede ser alto, si es capaz de subir los precios con facilidad y reducir la calidad del producto suministrado.

\section{Poder negociador de los compradores:}

El comprador de la ruta es la AA. VV Paradiso es la agencia cubana de turismo cultural que facilita al visitante conocer toda la riqueza que, heredada de la mezcla de culturas, y sus matices africanos y españoles, define a la nación caribeña. Este ofrece una variada programación que abarca distintos eventos relacionados con todas las manifestaciones artísticas e incluye, además, la formación académica. Paradiso es la única agencia que comercializa la producción de las instituciones culturales del país y la vanguardia artística, insertándose en la modalidad de turismo cultural. Además, se ofrecen programas culturales al turista que incluyen recorridos de ciudad, fiestas temáticas, visitas a instituciones culturales, proyectos comunitarios y escuelas de arte.

\section{$\underline{\text { Rivalidad entre los competidores existentes: }}$}

La situación de los competidores es de vital importancia en cuanto a la forma de manifestarse, teniendo en cuenta los recortes de precios, batallas de promoción, introducción de nuevos productos o modificación de estos. Al ser el comprador del producto la AA. VV Paradiso, no solo se tendrán como principales competidores otras 
rutas culturales que se desarrollen en otras provincias del país, sino que también las que sean implementadas en Camagüey; por ello es de vital importancia diferenciar el producto de otros.

\section{Productos sustitutos:}

Se considera que entre los productos sustitutos que mayor amenaza ofrecen al producto ofertado se encuentran las mismas instituciones que son visitadas durante la ruta, los cuales satisfacen la misma necesidad, aunque con un producto diferente. Entre ellas las iglesias San Juan de Dios y Nuestra Señora del Carmen y el Cementerio de Camagüey; la visita a las instalaciones de restauración y recreativas como la Casa de la trova, la campana de Toledo y la Tinajita, así como instalaciones que brinden el mismo servicio en la zona.

A partir del Análisis del Entorno Externo se pudieron identificar las oportunidades y amenazas para el desarrollo de la ruta turística:

Oportunidades:

- Ubicación privilegiada en el Centro Histórico de la ciudad como destino reconocido mundialmente y declarado Patrimonio de la Humanidad por la UNESCO.

- El crecimiento que ha experimentado la modalidad de Turismo Cultural como alternativa o complemento al Turismo de Sol y Playa.

- Actualización del Modelo Económico Cubano gracias a una serie de lineamientos algunos de ellos encaminados a potenciar el desarrollo de la industria turística.

Amenazas:

- La competencia del sector no estatal, así como de las mismas instituciones que brindan el mismo beneficio.

- Existen problemas con respecto a la dualidad monetaria, las tasas de cambio, entre otros que pudieran resultar un inconveniente para algunos visitantes.

El Análisis Interno permitió identificar las fortalezas y las debilidades siguientes: Fortalezas

- Única ruta histórico-cultural que permite a los turistas interesados, apreciar en ella la integración de la arquitectura, las leyendas, la historia, como parte de la cultura camagüeyana.

- Profesionalidad y capacitación del personal de contacto.

- Precios económicos y accesibles.

Debilidades:

- Existencia de un solo canal de distribución (AA. VV Paradiso) para la venta de nuestro producto.

- Dependencia de TRANSTUR S.A como proveedor fundamental de los minibuses. Una vez analizadas las Oportunidades, Amenazas, Fortalezas y Debilidades, se procedió a cruzar la Matriz DAFO con el objetivo de analizar la posición estratégica del producto. 


\begin{tabular}{llllllll}
\hline & & $\mathrm{O}$ & & & $\mathrm{A}$ & & \\
$\mathrm{F}$ & $\mathbf{1}$ & $\mathbf{2}$ & $\mathbf{2}$ & $\mathbf{1}$ & $\mathbf{2}$ & \\
& $\mathbf{1}$ & 3 & 3 & 2 & 2 & 0 & $\mathbf{1 0}$ \\
& $\mathbf{2}$ & 1 & 2 & 0 & 2 & 0 & $\mathbf{5}$ \\
& $\mathbf{3}$ & 3 & 3 & 2 & 2 & 0 & $\mathbf{1 0}$ \\
& & & & & & & \\
& $\mathbf{1}$ & 2 & 2 & 0 & 2 & 3 & $\mathbf{9}$ \\
& $\mathbf{2}$ & 1 & 2 & 0 & 2 & 3 & $\mathbf{8}$ \\
& & $\mathbf{1 0}$ & $\mathbf{1 2}$ & $\mathbf{4}$ & $\mathbf{1 1}$ & $\mathbf{6}$ &
\end{tabular}

Figura 1- Matriz de DAFO (Entrecruzamiento)

Fuente: Elaboración propia

Se realizó un análisis en base a criterios generales de segmentación, utilizando la variable geográfica, y se encontró que los principales emisores a Camagüey son visitantes provenientes de Canadá (con 205,4 miles de turistas días), Alemania (con 34,0 miles de turistas días) e Italia (con 15,4 miles de turistas días); presentando estos tres mercados la mayor cantidad de turistas días en el año 2014 y, observándose un incremento desde 2009 hasta el 2014. (Anuario estadístico de Camagüey 2014, s.f.). Luego se realizó la segmentación utilizando la técnica de análisis de clusters a partir de una encuesta realizada a turistas de estas nacionalidades en la ciudad Camagüey.

\section{Clúster 1}

Es el Cluster más amplio pues cuenta con 45 casos: 17 de Canadá, 8 de Italia y 20 de Alemania. La media del segmento por variables es de transporte: 7.84; gastronomía: 8,51; valores histórico- culturales: 7,96; por lo que este cluster le presta más importancia a la gastronomía. Observando la media, esta oscila entre 7 y 8 con una mínima diferencia y en el caso de la desviación estándar, la cual expresa la dispersión promedio de los valores de la variable con respecto a la media de la distribución de valores de dicha variable, se puede decir que la que menor grado de dispersión presenta es transporte con un valor de 0.48, lo que indica que es el valor más aceptado, a su vez le sigue gastronomía con 0.59 y en el caso de los Valores histórico- culturales con 0.93 que representa el valor más disperso con respecto a la media.

\section{Clúster 2}

Este Cluster cuenta con 15 casos, siendo 7 de Canadá, 5 de Italia y 3 de Alemania. La media del segmento por variables es de: transporte: 6.13, gastronomía: 7.00 y Valores histórico- culturales: 6.00, por lo que le dan mayor importancia a la gastronomía. Observando la media esta oscila entre 6 y 7 con una mínima diferencia y en el caso de la desviación estándar, se puede decir que la que menor grado de dispersión presenta es 
transporte con un valor de 0.99 , lo que indica que es el valor más aceptado, a su vez le siguen los valores histórico- culturales con 1.07 y en el caso de la gastronomía con 1.13 que representa el valor más disperso con respecto a la media.

\section{Clúster 3}

Este Cluster cuenta con 15 casos: 11 de Canadá, 2 de Italia y 2 de Alemania. La media del segmento por variables es de transporte: 6.27; gastronomía: 8.33 y valores históricoculturales: 8.80 , por lo que este segmento le da mayor importancia a los valores históricoculturales. Observando la media esta oscila entre 6 y 8 y en el caso de la desviación estándar, se puede decir que la que menor grado de dispersión presenta es gastronomía con un valor de 0.49 , le sigue transporte con 0.70 y los valores histórico- culturales con 0.77 .

Después de haber realizado el análisis de los tres clústeres encontrados, los autores decidieron enfocarse en el segmento No. 3, el cual está formado por personas provenientes de los tres principales mercados emisores a la ciudad de Camagüey (Canadá, Alemania e Italia) con edades que oscilan de 30 a 40 y de 50 a 60 años. En sus principales motivaciones de viaje están las vacaciones y el ocio, así como el interés de conocer el patrimonio material e inmaterial de los espacios visitados. Mayoritariamente viajan a través de una Agencia de Viajes y lo hacen con sus familias. Le prestan especial importancia a los valores histórico-culturales del destino que visitan y suelen quedarse de dos a cuatro días.

\section{Valores culturales del atractivo a partir del cual se forma la oferta.}

Quienes visitan la ciudad Camagüey, aunque sean reincidentes, no dejan de sucumbir al encanto de su trazado en forma de madeja, araña o plato roto. Aun así, nadie pierde la oportunidad de transitar por su centro urbano, declarado por la UNESCO como Patrimonio Cultural de la Humanidad el 7 de julio de 2008.

Este centro histórico será el protagonista de la ruta turística cultural que se propone, pues todos los lugares a los que hace referencia se encuentran dentro del mismo, el cual está distinguido por su trazado urbano irregular donde las calles y callejones camagüeyanos se caracterizan por su estrechez y sus diseños laberínticos ideados para desorientar a los piratas que azotaban la villa en siglos anteriores. Por eso, se hacen difíciles de transitar para aquellos que no las conocen, pero gustan de sus encantos. La arquitectura monumental y doméstica conforma un tejido urbano homogéneo donde es posible encontrar expresiones arquitectónicas correspondientes a diferentes períodos de la evolución de la villa.

El Centro Histórico, principal testigo de la riqueza patrimonial de la ciudad, fue declarado Monumento Nacional el 10 de noviembre de 1980. Tiene una extensión aproximada de más de 300 hectáreas, y es considerado el más grande de Cuba. En la misma se encuentra 
la síntesis y sedimento de las diversas expresiones culturales y de las diferentes etapas de su evolución. Transitar por esta zona permite apreciar mágicos ambientes urbanos intrínsecamente ligados a la historia y la cultura, donde la arquitectura y el urbanismo son consecuencia de la impronta humana en cada período.

El complejo sistema de plazas y plazuelas donde la vinculación templo, feligresía, plaza y trama, propios de la ciudad cristiana hispánica armonizan magníficamente- se complementa con edificios civiles y domésticos conjugados en un todo unitario, pero heterogéneo, y con un rico patrimonio intangible lleno de leyendas, tradiciones, costumbres vivas y un notable desarrollo cultural. El Centro Histórico de la Ciudad de Camagüey constituye un ejemplo relevante dentro del conjunto de ciudades coloniales. Su bien conservado repertorio religioso, el atípico trazado urbano irregular que mantiene vigencia en el presente, su alto valor ambiental y contextual; así como la sabia conjugación de pasado y modernidad, determinaron su inclusión en la Lista del Patrimonio Mundial.

A continuación, se ofrecerá una descripción de los valores culturales de las instalaciones y atractivos a partir de los cuales se conformará la ruta turística cultural.

\section{Parque de las Leyendas}

En la ciudad de Camagüey, se localiza el tranquilo y acogedor Parque de las Leyendas, cuyo mural es fruto de la mano, entre otros, del artista de la plástica Joel Jover. El sitio posee valor histórico, ambiental y social. En la instalación cultural se habla de siete leyendas de la Ciudad de los Tinajones. La más conocida, tanto en Cuba como en el extranjero, es la que advierte: "Del tinajón salían las aguas que tomaban lugareños y visitantes. Decía la tradición que el forastero que las bebiera siempre volverían al territorio." (Parque de las leyendas de Camagüey, un sitio para la contemplación, s.f.). Los textos de las leyendas fueron grabados en cerámica, y colocados al dorso del mural y la tapia posterior del parque; los paños de cerámica que se adosaron en la tapia son de 2000 x $3000 \mathrm{~m}$. y los paños colocados en la parte posterior del mural tienen 2000 × 2000 $\mathrm{m}$. Las áreas interiores del parque se rediseñan en función de un mejor aprovechamiento del espacio, se incrementa la capacidad de los bancos, y se incluyen en el mobiliario urbano las luminarias y papeleras.

\section{La Catedral}

Ubicada en la antigua Plaza de Armas, hoy Parque Agramonte, se alza la Parroquial Mayor, Catedral de la ciudad. Dedicada a Nuestra Señora de la Candelaria se declaró Santa Iglesia Catedral el 10 de diciembre de 1912, al quedar constituida la Diócesis de Camagüey, por el Papa Pio X. El 5 de diciembre de 1998 queda convertida en Catedral Metropolitana al ser constituido el Arzobispado de Camagüey con las diócesis de Ciego de Ávila, Santa Clara y Cienfuegos como sufragáneas. Resulta un lugar atractivo para visitar por su historia y arquitectura, por lo que será interesante su visita durante el recorrido. 


\section{Plaza San juan de Dios.}

La existencia del inigualable paraje en la ciudad de Camagüey data del Siglo XVIII (1728), según aparece en documentos de la antigua villa de Santa María del Puerto del Príncipe. El nombre del conjunto arquitectónico proviene de la orden de los Hermanos de San Juan de Dios. Allí se conserva la majestuosa arquitectura colonial que mantiene buena parte de la legendaria ciudad y pertenecen a este entorno la adoquinada plaza, junto al antiguo hospital, una iglesia y las viviendas, dos de ellas convertidas en unidades gastronómicas. Al sitio se llega desde la conocida Plaza de los Trabajadores después de un cercano recorrido por las enrevesadas calles y una vez allí los visitantes quedan atrapados por la singular belleza del lugar donde armonizan esculturas, pinturas y otros proyectos que poco a poco adquieren más fuerza para beneficio de la vetusta y bien conservada área que posee la bien ganada condición de Monumento Nacional.

\section{Iglesia y Convento-Hospital San Juan de Dios}

Posee su correspondiente iglesia, en cuyo altar mayor se encuentra la Santísima Trinidad con figura humana del Espíritu Santo, que es la única en Cuba y la segunda en Hispanoamérica. Su entorno lo constituye la Plaza de San Juan de Dios. Las primeras noticias de la iglesia y convento de San Juan de Dios datan de 1687 y 1692 en documentos relacionados con enterramientos que hablan de la ermita de San Juan de Dios o de Nuestra Señora de la Asunción respectivamente.

Conserva el antiguo ambiente enfatizado por el piso de ladrillos, techo de armadura de madera y tejas de barro, y los retablos de madera. Su fachada principal fue modificada entre los años 1847-1848 al ser reconstruida su torre lateral, esta vez a eje con su única puerta principal, lo cual la dotó de una marcada simetría. La torre está formada por cuatro cuerpos y rematada por una pequeña cúpula semicircular. Solo en los extremos presenta pilastras adosadas rematadas con un pequeño volumen rectangular terminado en pirámide, composición que se repite en lo alto de la torre. Bajo el piso de su altar mayor permanecen los restos mortales de sus benefactores Gaspar Alonso Betancourt Cisneros y su esposa Angela A. Hidalgo Agramonte, al igual que la señora María de la Trinidad Cisneros conocida como la Capitana o la Coronela debido a la graduación militar de su esposo, la cual hizo donación en 1792 de la interesante imagen de la Santísima Trinidad que preside el altar mayor del templo.

Un significativo hecho histórico tuvo lugar en este antiguo conjunto el 12 de mayo de 1873, al ser asistido en la galería de la planta baja del convento el cadáver del camagüeyano Ignacio Agramonte y Loynaz, Mayor General del Ejército Libertador cubano, luego de ser depositado por las tropas españolas en dicho sitio. El sacerdote Manuel Martínez Saltage y "el Padre Olallo" de los hermanos hospitalarios de la orden de los juaninos, asistieron y limpiaron el rostro de tan venerado patriota, al cual se le rindieron honores póstumos en el interior del convento antes de ser llevado a quemar. 


\section{Plaza del Carmen}

Justo en el callejón de Martí, uno de los más cortos del centro histórico, por contar solo con cuarenta pasos, se entrecruzan la calle Martí con la Plaza del Carmen. En la actualidad, el mayor encanto de esta plaza es el conjunto escultórico a tamaño natural donde la artista camagüeyana Martha Jiménez recreó la vida y costumbres de la comunidad. El conjunto está integrado por siete esculturas, modeladas en barro, a tamaño natural mediante la técnica del molde perdido, única de su tipo, según ha confesado la afamada artista. (RadioCadenaAgramonte.cu)

La Plaza del Carmen se ha convertido en lugar sui géneris por sus esculturas de personajes locales, sus jarrones y sus bancos. Precisamente, en uno de esos bancos se ha conocido a Norberto Subirats Betancourt, octogenario camagüeyano a quien la artista inmortalizó a través de la escultura de El lector sentado en un taburete de barro y marmolina molida. Otra de estas obras son tres chismosas frente a una silla vacía, obra con la cual se inició una leyenda, pues hoy muchas personas se sientan en ella y piden un deseo con la esperanza de que se lo concedan. La silla ha devenido símbolo de los sueños y esperanzas. Muchas son las razones para visitar esta plaza, considerada como el segundo Conjunto Colonial más conservado de la cuarta villa cubana, fundada por los españoles hace cinco siglos.

\section{Iglesia de Nuestra Señora del Carmen}

La Iglesia de Nuestra Señora del Carmen, ubicada en la Plaza del mismo nombre es el único templo en Camagüey de dos torres y fue el cuarto en construirse con estas características en Cuba. Aunque aparentemente su majestuosa fachada de tres accesos anuncia un edificio de tres naves, realmente posee una planta uninave de modestas proporciones con vestíbulo, coro, presbiterio y sacristía. Su fecha de construcción data de los años 1823 - 1825 .

\section{Museo Casa Natal de Ignacio Agramonte}

Esta Casa Museo constituye la vivienda con valor histórico más importante de la región. Se encuentra ubicado en el centro urbano de la ciudad de Camagüey. Allí nació el héroe epónimo de Camagüey: Ignacio Agramonte y Loynaz. Su distinción histórica y simbólica resulta el segundo índice de trascendencia, valor que adquiere crédito para la historia nacional, por ser el lugar donde naciera el prócer de la independencia de Cuba. Ambas razones fueron consideradas por la Comisión Nacional de Monumentos para declararla Monumento Nacional. (Publicitur S.A, 2014)

$\mathrm{Su}$ relevancia se centra en el valor arquitectónico del inmueble, que data, presumiblemente, de mediados del siglo XVIII y que recoge toda la huella hispánica, mudéjar y barroca, de la arquitectura colonial cubana, con influencias de otros estilos como el Neoclásico y Rococó. 
La Casa Museo dispone de una ambientación del siglo XIX, que muestra una secuencia propia de la época a través de muebles originales y piezas de artes decorativas. Dispone de una información histórica que recuenta la labor de Ignacio Agramonte en la Primera Guerra de Independencia. La Casa Natal de "El Mayor", como también se le llama, es un sitio que muestra los aspectos históricos y artísticos de la típica vivienda principeña.

\section{Cementerio de Camagüey}

El Cementerio General de Camagüey, el más antiguo en funcionamiento en Cuba, fue fundado el 3 de mayo de 1814, en lo que entonces se consideraba la periferia de la Villa de Santa María del Puerto del Príncipe; y hoy forma parte de una ciudad, Monumento Nacional y Patrimonio Cultural de la Humanidad. Como caso particular, no posee declaratoria de Monumento Nacional, y eso, por supuesto, repercute negativamente en la conservación, pues en el enfrentamiento cementerio-ciudad, siempre hay otras prioridades que lo relegan a un segundo plano de un largo alcance; pero, valores tiene muchos, incluso algunos que lo distinguen entre el resto de los cementerios patrimoniales de Cuba.

El Cementerio General de Camagüey, atesora un rico patrimonio arquitectónico, que mezcla estilos y llega hasta la modernidad, reflejado en las más de 10 mil construcciones funerarias, y cada una guarda un recuerdo, tiene una historia que contar. (Ecured.cu, s.f.). Este cementerio también puede contar su historia por los epitafios, algunos curiosos, otros de leyenda, singulares, de corte religioso, varios patrióticos, y hasta humorísticos. Algunos recientes marcan la historia del Cementerio General de Camagüey, pues la tradición no desaparece. Así se cuentan, entre otros, las curiosas inscripciones sobre la tumba del trovador Miguel Escalona: "Te debemos un trozo de vida empapado en alcohol". O la frase que acompaña los restos del pelotero Miguel Caldés: "Los buenos nunca dicen adiós". Y el epitafio de José Luis Moreno, conocido como El Diablo Moreno, corredor de motos: "Tu vida transcurrió veloz como tu moto y la entregaste al traspasar la meta de la gloria."

Es un museo a cielo abierto, dotado de un bagaje escultórico y monumental que hacen de él el espacio más decorado de la ciudad, con una iconografía peculiar, vinculada indisolublemente al ritual de la muerte y lo desconocido, y por eso, es diferente al resto de los museos tradicionales que los mortales conocen.

\section{La Campana de Toledo}

Casa colonial que data del siglo XVIII. Posee un bello patio con árboles y plantas ornamentales, el suelo con baldosas de barro, tejas coloniales y una sombra que en las tardes de verano brinda un poco de fresco.

Hay tinajones antiguos que antes se usaban para juntar agua y hoy sirven como elemento decorativo, algo bastante típico en esta ciudad que ha sido galardonada como Patrimonio Cultural de la Humanidad. La Campana de Toledo es un restaurante al que acude muchas personas, tanto de día como de noche, es un sitio típico, auténtico, donde se puede apreciar 
buena gastronomía cubana. Su especialidad es la comida criolla e internacional y cuenta con varias facilidades como el servicio de bar, y una estancia amenizada con música cubana y típica local, interpretada por un trío. (Palmares S.A, 2008)

\section{La Tinajita}

Consiste en otro restaurante del centro histórico que representa la comida típica camagüeyana donde el casabe, en diversas variantes forma parte de las ofertas gastronómica, el cual constituye uno de los alimentos más autóctonos y antiguos que pervive en Cuba, en disímiles platos culinarios. Una oferta que resultará atractiva para los visitantes. Antes del triunfo de la Revolución se conocía como el Bar de Don Pancho. A partir del año 1959 pasó a ser propiedad estatal. (Aguilar, 2017)

\section{Casa de la Trova}

Constituye una edificación colonial que data del año 1879, ubicada en el casco histórico de la ciudad de Camagüey. Perteneció al ilustre español don Manuel Cabaña en 1914, quien tenía una tienda mixta para la venta de instrumentos musicales, hasta el 17 de agosto de 1973 en que se funda como Casa de la Trova y se le da el nombre de Patricio Ballagas Palacios, en honor a tan insigne músico, compositor y patriota, nacido en esta ciudad en el año 1879 y que falleciera en la Habana en 1920. (Ecured.cu, s.f.). Brinda una variada programación cultural con una alta calidad donde se destacan varias actividades que se ofertan en la cartelera cultural de la casa.

\section{Marketing Mix}

\section{Producto}

El producto-servicio que se presenta a continuación, estará encaminado a satisfacer las necesidades de los clientes, contará con los servicios necesarios para cumplir sus expectativas de engrandecer su horizonte de conocimientos y experiencias, mediante la visita a varios lugares significativos pertenecientes al Centro Histórico de Camagüey: Joya de la nación cubana, joya de la humanidad.

Producto básico: Ofrecer al cliente un acercamiento a la cultura e historia del Centro Histórico de Camagüey, como Joya de la nación cubana y de la humanidad. Producto tangible: Recorrido de tipo cultural por diferentes lugares emblemáticos del Centro Histórico de Camagüey que muestren lo más autóctono de la región: leyendas, historia, arquitectura (cultura en modo general).

Producto aumentado: Obsequio a cada cliente de un souvenir en forma de tinajón, que constituye el símbolo que representa a esta provincia. Esta ruta tiene como objetivo ofrecer un producto turístico cultural, que permita a los clientes, apreciar mágicos ambientes urbanos, e instituciones intrínsecamente ligados a la historia y la cultura, donde la arquitectura y el urbanismo son consecuencia de la impronta humana en cada período.

Nombre del producto: Laberinto de Leyendas y Tradiciones 
Localización: Centro Histórico de Camagüey

Atractivos que se visitan:

- $\quad$ Parque de las leyendas

- La catedral

- Casa de Ignacio Agramonte

- Restaurante La Tinajita

- Plaza del Carmen

- Iglesia Nuestra Señora del Carmen

- Cementerio General de Camagüey

- $\quad$ Plaza san Juan de Dios

- Iglesia San Juan de Dios

- La campana de Toledo

- La Casa de la Trova

Tiempo del recorrido: 12 horas y 20 minutos

Capacidad: 15 pax

Explicación del itinerario: La ruta está concebida para cualquier temporada del año, indistintamente cualquier día de la semana. Su horario estará comprendido entre las 9:30 am hasta las10:00pm.

- 9:20am: se recogerá a los turistas en el hotel, donde se les dará a conocer una panorámica del recorrido.

- A las 9:30am se dará inicio al recorrido por el Parque de las leyendas donde se le explicará en la instalación cultural siete principales leyendas de la Ciudad de los Tinajones, donde algunas formarán parte del recorrido.

- 10:10am-10.40am: Se visitará La Catedral, donde se dará un recorrido por sus diferentes locales.

- 10.50am-11:30am: Se realizará un recorrido por la Casa natal de Ignacio Agramonte, Casa Museo que constituye la vivienda con valor histórico más importante de la región, donde se ofrecerá información general del museo en relación con la vida de Ignacio Agramonte y Loynaz, su presencia en la Guerra del 68 en Camagüey.

- 11:40am-1:00pm: Los clientes podrán degustar de un maravilloso almuerzo en La Tinajita, cuya especialidad es la comida tradicional cubana, espacio que será aprovechado para hacer entrega de un suvenir en forma de tinajón como recuerdo del recorrido.

- 1:10pm-1:40pm: Se dará un recorrido por la Plaza del Carmen, donde los clientes podrán apreciar el segundo Conjunto Colonial más conservado de la cuarta villa cubana, entre sus atractivos se encuentra la presencia de esculturas de personajes locales que han sido generadora de leyendas.

- 1:40pm-2:30pm: Se visitará la Iglesia Nuestra Señora del Carmen, único templo en Camagüey de dos torres, donde la arquitectura será el principal atractivo. 
- 2:40pm-3:30pm: Se pasará a recorrer el Cementerio General de Camagüey mediante el cual los clientes podrán apreciar como esta institución atesora un rico patrimonio arquitectónico, que mezcla estilos y llega hasta la modernidad, reflejado en las más de 10 mil construcciones funerarias, y cada una guarda un recuerdo, tiene una historia que contar.

- 3:40pm-4:30pm: Se visitará la Plaza San Juan de Dios que constituye el conjunto urbanístico mejor conservado del pasado colonial y es la plaza más antigua de la ciudad.

- 4:40pm-5:30pm: Se recorrerá la iglesia San Juan de Dios, templo donde los turistas podrán apreciar que tiene en su altar mayor, la imagen de la Santísima Trinidad en madera preciosa (una de las 2 que existen en Hispanoamérica).

- 5:40pm: Se llevará a los turistas al hotel para el hotel donde contarán con 1 hora aproximadamente libre, hasta la comida.

- 7:00pm: se recogerá a los turistas del hotel y se les llevará a degustar de buena comida criolla e internacional en el restaurante La Campana de Toledo.

- $\quad$ Posteriormente a las 8:20pm se les llevará a la Casa de la Trova, donde podrán finalizar la noche con buena música cubana hasta la 10:00pm que se trasladarán hacia el hotel.

\section{Recursos requeridos para el desarrollo de la ruta:}

Recursos Humanos: 1 guía turístico especializado en la historia y cultura de Camagüey, 1 chofer, y 8 personas que manejen bici-taxis.

\section{Recursos materiales:}

* 8 bicis taxis, pertenecientes al proyecto artístico Andariego, quienes, como una forma de llevar las artes plásticas de las galerías de pintores a las calles, retocaron los dibujos de los bici-taxis de la Empresa de Servicios Santa María, de la Oficina del Historiador de la Ciudad de Camagüey.

* Un minibús durante 5 horas en la tarde y noche.

* Un botiquín de primeros auxilios por si ocurre algún incidente.

\section{Personal:}

Como se conoce el capital humano es uno de los elementos que diferencian al producto, y puede constituir un componente competitivo a nuestro favor, por ello es necesario asegurarse de que responda a los intereses del mismo. En este sentido es importante el proceso de reclutamiento y selección de los guías turísticos. Este proceso se realiza según la forma convencional, es decir, se basa principalmente en buscar las capacidades y conocimientos del candidato al puesto con respecto a la cultura y el dominio de varios idiomas, por lo que, a los fines de reforzar un enfoque de marketing se le debe incorporar elementos en su evaluación tales como los valores personales - profesionales, así como aspectos de características personales que consoliden la propensión al cambio puesta de manifiesto en el personal y un claro enfoque al cliente. (Serra, 2003). Es importante tener siempre en cuenta que el personal de contacto se considere bien recompensado en cuanto 
a salario, atendiendo a las condiciones y posibilidades reales del país. Además, es necesario compensar a los trabajadores por sus méritos a través de premios e incentivos materiales.

\section{Precio}

Para la determinación del precio de la propuesta de ruta turística cultural que potencializará los atractivos y productos turísticos culturales de la ciudad Camagüey, se tuvieron en cuenta aspectos fundamentales como el precio que está dispuesto a pagar la demanda y los precios de la competencia. Una vez analizados los mismos se procedió al cálculo de los costes de la ruta.

En la ruta se utilizarán dos medios de transporte: 8 Bici-taxis y 1 guagua de TRANSTUR. Los Bici-taxis serán utilizados de 9:20 am a 6:00 pm para un recorrido de $40 \mathrm{~km}$; su tarifa es de 1.00 CUC por km, por lo que en total sería un coste de 320.00 CUC. Según las tarifas de la Empresa de Transporte Turístico TRANSTUR, una guagua de 24 plazas que recorra hasta $10 \mathrm{~km}$ por 5 horas tendrá un coste total de 84.40 CUC. Un guía de la Agencia de Viajes Paradiso cobra 5.00 CUC la hora y, teniendo en cuenta la duración de la ruta será un costo total de 60.00 CUC. Por otra parte, la entrada a la casa museo de Ignacio Agramonte es de 4.00 CUC por pax y al ser esta ruta diseñada para 15 pax, en total serían 60.00 CUC.

El coste del almuerzo en la Campana de Toledo, que es comida criolla, es de 12.00 CUC por pax, por lo que en total serían 180.00 CUC. Por su parte la comida tradicional cubana en La Tinajita oscilará entre los 5.00 y 10.00 CUC. La entrada a la Casa de la Trova es de 5.00 CUC y los tragos a consumir pueden ser desde 1.50 CUC hasta 3.00 CUC. Por su parte el costo de los souvenires será de 1.00 CUC. En la estimación del precio también se incluye el margen de ganancias de la Agencia de Viajes Paradiso será del 10\%.

\begin{tabular}{|c|c|}
\hline Costos Variables & Costos Variables Totales \\
\hline $\begin{array}{l}\text { Entrada a la casa museo de Ignacio } \\
\text { Agramonte }\end{array}$ & $4.00 \mathrm{CUC} \times 15 \mathrm{pax}=60.00 \mathrm{CUC}$ \\
\hline Almuerzo en la Campana de Toledo & 13.00 CUC $\times 15$ pax $=195.00$ CUC \\
\hline Comida en La Tìnajita & $10.00 \mathrm{CUC} \times 15 \mathrm{PAX}=150.00 \mathrm{CUC}$ \\
\hline Entrada a la casa de la trova & 5.00 CUC $\times 15$ pax $=75.00$ CUC \\
\hline Mojito & 3.00 CUC $\times 15$ pax $=45.00 \mathrm{CUC}$ \\
\hline Daiquirí & 3.00 CUC $\times 15$ pax $=45.00$ CUC \\
\hline Cuba Libre & $1.50 \mathrm{CUC} \times 15 \mathrm{pax}=22.50 \mathrm{CUC}$ \\
\hline Souvenires & $1.00 \mathrm{CUC} \times 15 \mathrm{pax}=15.00 \mathrm{CUC}$ \\
\hline Total & $607.50 \mathrm{CUC}$ \\
\hline Costos Fijos & Costos Fijos Totales \\
\hline Guagua & $84.40 \mathrm{CUC}$ \\
\hline Bici- taxis & 320.00 CUC \\
\hline Servicio de Guía & $60.00 \mathrm{CUC}$ \\
\hline Total & 464.40 CUC \\
\hline
\end{tabular}

Figura 2. Tablas de costos variables y fijos.

Fuente: Elaboración propia. 
Costo fijo unitario (Cfu) 464.40/15=30.96 cuc

Costo variable unitario $(\mathrm{Cvu}) 607.50 / 15=40.50 \mathrm{cuc}$

Costos Totales (variables y fijos $)=464.40+607.50=1071.90 \mathrm{cuc}$

Precio unitario antes de comisión $=1071.90 \mathrm{cuc} / 15 \mathrm{pax}=71.46 \mathrm{cuc}$

$5 \%$ unitario de ganancias para la AA. $\mathrm{VV}=3.573 \mathrm{cuc}$

Precio estimado $=75.03$ cuc

Precio unitario: $\mathrm{Pu}=\mathrm{Cfu}+\mathrm{Cvu}+$ Beneficios AAVV

$\mathrm{Pu}=30.96 \mathrm{cuc}+40.50 \mathrm{cuc}+3.573 \mathrm{cuc}$

$\mathrm{Pu}=75.033$, aproximadamente $75.00 \mathrm{cuc}$

El precio estimado para la ruta por pax es de $75.00 \mathrm{CUC}$

\section{Promoción}

Es sabido que toda estrategia dirigida a la promoción de un producto turístico debe trabajar en el objetivo de generar en el viajero una experiencia satisfactoria que refuerce sus lazos emocionales con el producto y favorezca así la recomendación, pero el esfuerzo ahora debe ser mayor, se debe salir de la cómoda postura de ser simples oferentes del producto y abrir el abanico para atender las múltiples posibilidades que tiene el usuario de llegar hasta el producto.

En correspondencia con este proyecto en el que se ha propuesto la creación de una ruta turística cultural que potencializará los atractivos y productos turísticos de la ciudad Camagüey, se ha diseñado una propuesta de promoción para posicionar a la misma en el segmento de demanda objetivo.

Esta campaña de promoción tiene como ojetivo fundamental el de cautivar al segmento de la demanda delimitado con los atributos del producto para que se sientan atraídos a viajar a la ciudad y compren la ruta diseñada. Una vez establecido el objetivo principal de dicha campaña a continuación se expondrán los instrumentos y técnicas de promoción a utilizar:

- Se utilizará el principal canal de distribución, la Agencia de Viajes Paradiso, incluyendo la ruta diseñada en los paquetes turísticos que se conformen o venderla como opcional.

- Se hará uso de todo tipo de material impreso (folletos, catálogos y similares)

- Se promocionará y comercializará a través de la Internet con la página web que promociona el destino Camagüey y la de la Agencia de Viajes Paradiso.

\section{Distribución (Place)}

Es necesario conocer que con una distribución adecuada se puede incrementar la accesibilidad del consumidor a la información de los servicios y hacer más fácil la reservación. Para la colocación de este producto en el mercado, la agencia de viajes especializada Paradiso, única promotora del turismo cultural como modalidad en Cuba es 
la encargada de comercializarlo, colocando la ruta entre los nuevos productos turísticos novedosos y que por su parte llevará a cabo la venta de la ruta en el Buró de Ventas de cada hotel. Por otra parte, las Tecnologías de la Información y la Comunicación juegan un papel primordial como medios de difusión. La utilización de redes sociales permite promover nuestro producto con la utilización de visitas virtuales a nuestro destino, que les posibilitan a nuestros clientes potenciales conocer los productos antes de visitarnos, haciéndose una idea más real de lo que recibirá y evitar una futura insatisfacción; por lo que es necesario utilizar la página web de la Agencia de Viajes para introducir la información general acerca de la ruta turística, y colocarla en todos las oficinas de INFOTUR como parte de libros de guía turística de Camagüey.

\section{Factibilidad Económica}

Para la fijación del precio de la ruta por pax se tuvieron en cuenta los costos fijos y variables del producto, tomando en consideración los precios preferenciales que le dan los prestatarios a las agencias de viajes. Para la determinación del precio se tuvo en cuenta un $5 \%$ de beneficio para la Agencia de Viajes Paradiso, concluyendo que el precio final por pax es de 75.00 CUC. Esta ruta es factible económicamente debido a que tiene un precio estimado asequible para el segmento de demanda objetivo y, al ser una ruta con atributos que la hacen diferente y novedosa, tendrá éxito rápidamente, por lo que contribuirá al crecimiento económico de la ciudad y de la provincia; potencializando los atractivos y productos turísticos culturales de Camaguiey.

\section{Factibilidad Medioambiental}

Como es conocido los impactos ambientales son los efectos que producen una determinada acción humana sobre el medio ambiente en sus distintos aspectos. Estos pueden ser originados, haciendo referencia a la actividad turística, el exceso de capacidad de carga del destino, la actividad de los propios turistas y por la construcción de infraestructura. Con respecto al producto que se plantea desarrollar en este trabajo se puede decir que esta ruta turística contribuye de cierta forma al intercambio cultural, propiciando el entendimiento entre varias culturas: la de los turistas provenientes de varias partes del mundo y la cubana. Es necesario indicar que el desarrollo de este producto turístico es factible desde el punto de vista medioambiental ya que la ruta en sí no contribuye al deterioro del medio ambiente, ni depende, al menos de forma directa, de la explotación de valiosos y escasos recursos naturales, respeta y se acoge a todas las leyes y políticas medioambientales. Es significativo señalar el alto grado de responsabilidad social que llevan incluido estas actividades, promoviendo el rescate de importantes valores culturales y favoreciendo al desarrollo de una actividad turística sostenible. Por lo que según el diseño que se ha analizado y realizado de este producto, no trae consecuencias negativas a la zona donde se desarrolla.

Problemática ambiental: La estrategia del trabajo ambiental en esta provincia, la más extensa del país y con la mayor área de costas, tiene su centro en la integración de las 
empresas e instituciones que cumplen con los encargos de la gestión ambiental, a través de los programas y políticas diseñadas para la educación, la preservación de la diversidad biológica y el cuidado del entorno.

No obstante, la ciudad de Camagüey no está exenta de problemas ambientales y entre los principales identificados se encuentran los siguientes:

- La contaminación de aguas superficiales y subterráneas, lo que trae como consecuencia insuficiente disponibilidad de agua potable y pérdida de este recurso.

- Problemas relacionados con el estado de las construcciones en la zona de forma general: debido a al alto grado de deterioro del fondo habitacional, que trae como consecuencia que afecte directamente a la población que habita allí.

- La insuficiente cultura ambiental y afectación de las condiciones higiénicosanitarias de las comunidades, que perturba a la comunidad y al desarrollo del turismo que pueda generarse en la zona.

Los impactos positivos que puede generar la creación e implementación de este producto turístico se considera que los principales son: que puede ser un medio para preservar las instalaciones y espacios que se visitan, incrementando de esta forma la conciencia ambiental de los ciudadanos de proteger el entorno, además de ser una fuente generadora de empleo, destaca y promueve valores culturales existentes en el municipio que reflejan la cultura de Cuba y que la hacen inigualable. Es necesario decir que un medio importante de transporte que se utiliza en la ruta lo constituyen la bici taxis, por lo que no generan daños al entorno. También se considera que puede aumentar el nivel de vida de sus habitantes, al generar ingresos a la zona, pues una parte de ellos puede ser utilizada para restaurar los lugares de interés histórico y cultural (esto puede ser considerado como una inversión y no un gasto debido a que permitirá posteriormente generar beneficios económicos), además de que los habitantes de la zona podrán desarrollar negocios que complemente la ruta turística. Entre los impactos negativos que puede el producto generar a la zona está el hecho de que los turistas provenientes de países industrializados, utilizan más agua y otros recursos y generan más basura por persona, que los residentes en países en desarrollo y la contaminación del aire que genera por el uso de vehículos es mayor, no obstante, nuestro producto no ocasiona daños directos al entorno.

\section{Buenas prácticas ambientales en aras de un desarrollo satisfactorio de la ruta:}

Para poder realizar esta ruta turística cultural preservando el entorno se deben tener en cuenta una serie de elementos que contribuirán a un mejor desarrollo de la misma. Entre ellos citamos que por desarrollarse en un espacio urbano debe enfocarse en la preservación del patrimonio tangible a través de la aplicación de una serie de medidas como: velar para que los turistas no arrojen desechos sólidos a las calles, y que no dañen el patrimonio histórico-cultural. El diseño de esta ruta está encaminado a desarrollar un turismo sostenible donde los turistas puedan establecer un vínculo entre la historia, la cultura y la conservación de los recursos naturales. Lo cual requiere una adecuada y 
responsable planificación, considerando políticas y criterios de desarrollo, que incorporen principios de sostenibilidad y que infunda en la mente del ciudadano una adecuada cultura medioambiental, dirigida al cuidado y preservación de la ciudad, garantizando así el bienestar de la sociedad en su conjunto.

\section{Definición de estrategias y acciones para la introducción de la oferta en el mercado}

Luego de haber diseñado esta ruta turística cultural, habiendo realizado los respectivos análisis de la determinación del precio, de los canales de distribución, de la forma de promoción, así como una evaluación de la factibilidad económica y medioambiental, se hace necesario entonces definir las estrategias para la introducción de la ruta en el mercado, además de realizar una planificación estratégica de las posibles estrategias a desarrollar en esta fase inicial de vida del producto.

Teniendo en cuenta que la ruta es un producto de nueva creación, esta se encuentra en la fase de introducción, por lo que el nivel de riesgo es elevado, pues los costos iniciales son altos a causa de los gastos generados en la promoción y otras inversiones iniciales; no se obtienen utilidades todavía y existen bajos volúmenes de venta que irán aumentando lentamente. En esta fase, las estrategias a seguir serán:

1. Implementar las nuevas tecnologías para la promoción y posicionarse en el mercado.

2. Establecer alianzas con los prestatarios de los distintos servicios, fundamentalmente de la transportación (TRANSTUR y la Oficina del Historiador de la ciudad, en cuanto al proyecto de los Bici- taxis).

Por otra parte, se considera que como estrategia genérica competitiva a emplear la más acertada es mediante la diferenciación del producto, mostrando las ventajas que el mismo ofrece, de forma que. Lo anteriormente expuesto permitirá garantizar el posicionamiento del producto en el mercado y elevar el nivel de ventas, lo que a su vez aumentará los beneficios para la Agencia de Viajes Paradiso.

\section{Conclusiones.}

- El entorno de la ciudad Camagüey resulta favorable para la implementación de la ruta turística cultural «Laberinto de leyendas y tradiciones».

- Camagüey es poseedora de grandes valores histórico-culturales que deben ser aprovechados en el desarrollo de la actividad turística en su modalidad de turismo cultural.

- La ruta turística cultural «Laberinto de leyendas y tradiciones» es factible económica y medioambientalmente puesto que el diseño de esta ruta está encaminado a desarrollar un turismo sostenible donde los turistas puedan establecer un vínculo entre la historia, la cultura y la conservación de los recursos 
naturales y además económicamente, tiene un precio estimado asequible para el segmento de demanda objetivo y, al ser una ruta con atributos que la hacen diferente y novedosa contribuirá al crecimiento económico de la ciudad y de la provincia, a medida que vaya teniendo éxito.

- El éxito de la ruta está garantizado gracias al desarrollo de estrategias que se implementarán desde su fase introductoria en el mercado, como el aprovechamiento de las nuevas tecnologías para la promoción, además de otras que contribuirán a un mejor posicionamiento en el mercado y permitirán diferenciar al producto.

\section{Referencias Bibliográficas.}

Colectivo de autores. (2009). Modalidades Turísticas. La Habana: Félix Varela.

Aguilar, O. S. (2017). Adelante.cu. Obtenido de La Tinajita rescata sus tradiciones: http:/adelante.cu

Ecured.cu. (s.f.). Obtenido de Cementerio General de Camaguey: http://www.ecured.cu

Fernández, M. (s.f.). Turismo Histórico en Cuba. Ciudad de Camagüey. Obtenido de http://viajarxcuba.com/.

(s.f.). Lineamiento No. 261, aprobado en el VI Congreso del PCC.

Martín, R. (2009). Principios, Organización y Prácticas del Turismo. La Habana: Félix Varela.

Palmares S.A. (2008). Guía de productos Camagüey. Publicitur.

Parque de las leyendas de Camaguiey, un sitio para la contemplación. (s.f.). Obtenido de hicuba.com: https://www.hicuba.com/index.htm

Publicitur S.A. (2014). Guías temáticas. Primeras villas cubanas. Camaguey.Lugares de interés. Cuba.

RadioCadenaAgramonte.cu. (s.f.). Obtenido de La Plaza del Carmen donde se funden Historia y tradición: Http:/radiocadenaagramonte.cu

Serra, A. (2003). Marketing Turístico. ESIC.

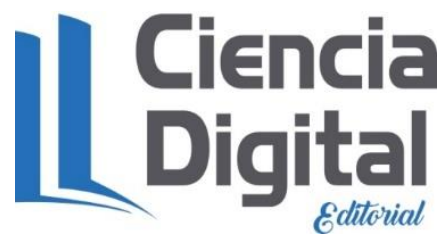




\section{PARA CITAR EL ARTÍCULO INDEXADO.}

Arceo Martínez, A., \& Malvarez Cuello, A. (2021). Diseño de la ruta turística cultural "Laberinto de leyendas y tradiciones". Explorador Digital, 5(2), 50-73.

https://doi.org/10.33262/exploradordigital.v5i2.1652

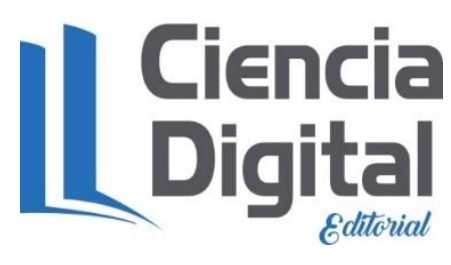

El artículo que se publica es de exclusiva responsabilidad de los autores y no necesariamente reflejan el pensamiento de la Revista Explorador Digital.

El artículo queda en propiedad de la revista y, por tanto, su publicación parcial y/o total en otro medio tiene que ser autorizado por el director de la Revista Explorador Digital.
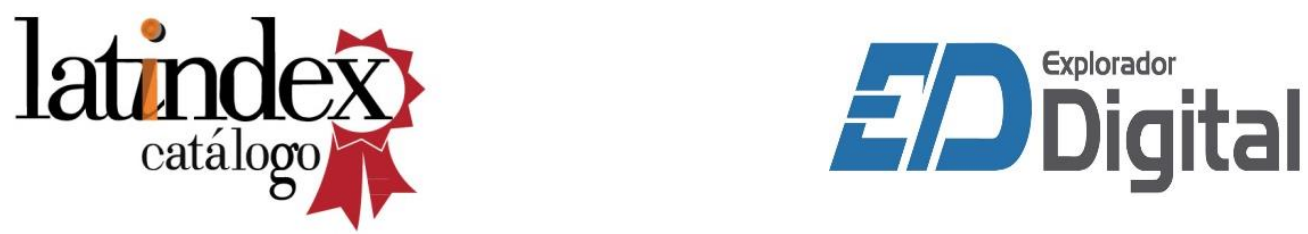